\title{
A QUESTÃO METODOLÓGICA NA PRODUÇÃO VIGOTSKIANA E A DIALÉTICA MARXISTA
}

Nancy Romanelli

\begin{abstract}
RESUMO. Pretende-se, neste artigo, abordar algumas formulações de Vigotski referentes ao campo metodológico. Destacando-se a significativa influência das ideias de Marx e Engels na produção do psicólogo bielorrusso, procurou-se: a) apontar a crítica de Vigotski às aplicações simplistas do materialismo histórico e dialético à psicologia; b) resgatar a proposta elaborada pelo autor para a psicologia geral; c) indicar alguns instrumentos metodológicos elaborados pelo próprio psicólogo; d) identificar, na busca teórico-metodológica de Vigotski, os pressupostos dialético-marxistas. A retomada, no presente estudo, das investigações metodológicas de Vigotski suscitou as seguintes conclusões preliminares: a) a pesquisa pontual e as formulações gerais representam dois níveis indissociáveis na abordagem históricocultural; b) a análise dialético-materialista dos dilemas epistemológicos da psicologia está diretamente vinculada ao campo mais amplo da produção científica; c) a específica forma pela qual Vigotski integrou o legado marxista à psicologia tem potencial para contribuir, também, com outras áreas do saber.
\end{abstract}

Palavras-chave: Materialismo dialético; Vigotski; método.

\section{THE METHODOLOGICAL QUESTION IN THE VIGOTSKIAN PRODUCTION AND MARXIST DIALECTICS}

\begin{abstract}
In this essay, we attempt to approach certain formulations posed by Vigotski in the methodological field. Highlighting the notable influence of Marx's and Engel's ideas upon the work of the byelorussian psychologist, we have aimed at: a) pointing out Vigotski's criticism to the simplistic applications of historical and dialectical materialism to psychology; b) bringing back the proposal elaborated by the author to the general psychology; c) indicating certain methodological instruments elaborated by the psychologist himself; d) identifying, in Vigotski's theoretical and methodological search, the marxist dialectical presuppositions. The undertaking, in this present study, of Vigotski's methodological inquiries has brought forth the following preliminary conclusions: a) the specific search and the general formulations represent two indissoluble levels in the cultural-historical approach; b) the dialectical-materialist analysis of psychology's epistemological dilemmas is directly linked to the broader field of scientific production; c) the specific manner by which Vigotski has integrated the marxist legacy to psychology is potentially able to contribute, also, to other areas of knowledge.
\end{abstract}

Key words: Dialectical materialism; Vigotski; method.

\section{LA CUESTIÓN METODOLÓGICA EN LA PRODUCCIÓN VIGOTSKIANA Y LA DIALÉCTICA MARXISTA}

RESUMEN. En este artículo se pretende examinar algunas formulaciones de Vigotski en el campo metodológico. Se pone de relieve la significativa influencia de las ideas de Marx y Engels en la producción del psicólogo bielorruso, y se procura: a) exponer la crítica de Vigotski contra las aplicaciones simplistas del materialismo histórico y dialéctico a la psicología; b) rescatar la propuesta del autor para la psicología general; c) indicar algunos instrumentos metodológicos elaborados por el autor; d) identificar, en la búsqueda teórico-metodológica de Vigotski, las presuposiciones dialéctico-marxistas. La retomada, en este estudio, de las investigaciones metodológicas de Vigotski permitió las siguientes conclusiones liminares: a) la investigación particular y las formulaciones generales representan dos niveles indisociables en el enfoque histórico-cultural; b) el análisis dialéctico-materialista de los dilemas epistemológicos de la psicología se relaciona directamente con el campo más amplio de la producción científica; c) la forma específica en la que Vigotski integró el legado marxista a la psicología tiene potencial para contribuir, también, a otras áreas de conocimiento.

Palabras-clave: Materialismo dialéctico; Vigotski; método.

Mestre em Educação pela Faculdade de Educação da Universidade de São Paulo (FEUSP), especialista em psicologia escolar pelo Instituto de Psicologia da Universidade de São Paulo (IPUSP) e psicóloga escolar pela Prefeitura Municipal de São Bernardo do Campo. 
Tenho defendido a ideia de que para se analisar um dado objeto de estudo a partir da obra de Lev Semenovich Vigotski ${ }^{1}$ (1896-1934) é fundamental levar em conta as discussões metodológicas e as contingências históricas que marcaram o desenvolvimento da produção do psicólogo bielorrusso - afinal, Vigotski, além de um importante teórico da psicologia, foi um dos grandes epistemólogos dessa ciência, e sua busca pelo conhecimento sempre esteve aliada às prementes necessidades de seu tempo histórico.

Tentar apreender a dimensão metodológica em uma obra que estabeleceu interfaces com vários campos do conhecimento e que vem sofrendo as mais diversas interpretações, como é o caso da de Vigotski, constitui-se em uma empreitada deveras desafiadora. Em face da complexidade da tarefa aqui apresentada e da exiguidade do espaço de discussão de um artigo, pretendo, neste estudo, tão somente fazer uma modesta introdução, de cunho bibliográfico, à perspectiva metodológica vigotskiana. Para tanto, primeiramente, apresentarei a filiação dialéticomarxista das ideias de Vigotski; em seguida, retomando brevemente o contexto histórico russosoviético, pinçarei alguns eixos temáticos que orientaram a busca vigotskiana por uma psicologia geral fundamentada no método materialista dialético; por fim, resgatarei alguns importantes sustentáculos metodológicos da abordagem histórico-cultural, relacionando-os ao método dialético-marxista. Almejo assim contribuir, de alguma forma, para um melhor entendimento da estreita relação que Vigotski estabeleceu entre pesquisa teórica e pesquisa metodológica.

De fato, foi intensa, original e profunda a proposta vigotskiana de investigar as bases epistemológicas da ciência psicológica e de demonstrar que visões de mundo e concepções metodológicas são indissociáveis da pesquisa científica. De acordo com uma pesquisadora da psicologia soviética, "qualquer teoria científica, especialmente nas chamadas ciências humanas, responde a uma concepção geral sobre a essência do homem, sua origem, a natureza do conhecimento,"

\footnotetext{
Várias transliterações têm sido adotadas para o sobrenome do autor: Vigotsky, Vygotski, Vygotsky, Vigotskii, Vigotski. Optei por "Vigotski", adotando a grafia sugerida pelo tradutor Paulo Bezerra, que verteu para o português, a partir dos originais russos, algumas produções do psicólogo, como, por exemplo, Psicologia da Arte (Vigotski, 1999c) e A Construção do Pensamento e da Linguagem (Vigotski, 2001). Contudo, nas citações literais, respeitarei as grafias contidas nos textos consultados.
}

entre outros fatores (Shuare, 1990, p. 13, tradução nossa). Como enfatizam dois outros psicólogos, a dimensão filosófica e a concepção de mundo cumprem "uma função metodológica geral na investigação psicológica" e, dessa forma, contribuem para assegurar a objetividade e o "caráter científico dos resultados obtidos em uma dada investigação" (Zinchenko \& Smirnov citado por Shuare, 1990, p. 1213).

Ao abordar a dimensão metodológica na obra vigotskiana somos imediatamente transportados para uma época marcada por acirrados debates epistemológicos no campo da produção científica. É inevitável nos perguntarmos contra o quê e a favor de quê o autor bielorrusso travou seus embates e tentarmos compreender as sínteses metodológicas que ele empreendeu, tanto no campo da ciência psicológica quanto em sua abordagem históricocultural. Para nos situarmos em relação a esses questionamentos, cabe retomar, antes de tudo, algumas inquietações epistemológicas que alimentaram o trajeto intelectual de Lev Vigotski.

\section{AS PREOCUPAÇÕES FILOSÓFICO- METODOLÓGICAS DE VIGOTSKI}

Para discutirmos a questão metodológica na produção de Vigotski, cabe mencionar que, para o autor, o termo "método", grosso modo, conjuga duas acepções que são básicas mas se mesclam: 1) método de pesquisa (no sentido dos procedimentos técnicos a serem colocados em prática) e 2) método epistemológico (a perspectiva filosófica mais geral, que direciona a pesquisa). Essas duas perspectivas são indissociáveis e se retroalimentam em um estudo científico de orientação dialética, estudo esse denominado por Vigotski de metodologia (Vigotski, 1927/1999b).

Reconhecido como um dos grandes nomes da Psicologia do séc. XX, Vigotski sempre mostrou interesse pelo conhecimento filosófico e pela produção artística, estabelecendo, em suas pesquisas em psicologia, interfaces com os campos da estética, semiótica, pedagogia, epistemologia e outros; porém esses campos de investigação, os estudos experimentais por ele conduzidos e grande parte de sua produção teórica foram permeados por uma preocupação central: a busca pelos específicos fundamentos metodológicos da ciência psicológica. Como indicou Alexei Nikolaevich Leontiev (19031979), um renomado psicólogo que trabalhou diretamente com Vigotski, foi a questão do método que orientou a obra vigotskiana, ainda que as 
investigações do autor bielorrusso tenham representado "apenas a primeira etapa" de um amplo programa teórico e metodológico (Leontiev, 1999, p. 426).

Vejamos um primeiro exemplo dessa preocupação de Vigotski com o método, resgatando algumas interfaces que o autor estabeleceu entre a arte e a psicologia. Discorrendo sobre suas estratégias metodológicas no texto "O significado histórico da crise em psicologia" (um manuscrito concluído em 1927 e publicado postumamente) (Vigotski, $1927 / 1999 b)^{2}$, o autor deixa clara, antes de tudo, a influência que sofreu da obra de Marx e Engels. Reportando-se às análises literárias (sobre a fábula, o conto e a tragédia) que ele próprio realizou em sua tese de doutorado Psicologia da Arte (um estudo concluído em 1925 e publicado postumamente) (Vigotski, 1925/1999c), o autor relata quanto se inspirou na tese marxista de que "a análise do homem é a chave da anatomia do macaco" (Marx, 1844/1978a, p. 120) (a ideia de que o estudo de condições mais elaboradas permite compreender formas mais simples):

[...] parti da ideia de que as formas mais desenvolvidas da arte são a chave das formas atrasadas, como a anatomia do homem o é em relação à dos macacos; que a tragédia de Shakespeare nos explica os enigmas da arte primitiva e não ao contrário. Além do mais, faço afirmações sobre toda $a$ arte e não comprovo, no entanto, minhas conclusões na música, na pintura etc. Mais ainda: não as comprovo sequer em todas ou na maioria das variedades de literatura; tomo somente um conto, uma tragédia. Com que direito? Não estudei as fábulas nem as tragédias e menos ainda uma dada fábula e uma dada tragédia. Estudei nelas o que constitui a base de toda a arte: a natureza e o mecanismo da reação estética. Apoiei-me nos elementos gerais da forma e do material inerentes a toda a arte. Escolhi para a análise a fábula, o conto e a tragédia mais difíceis, precisamente aqueles em que são especialmente patentes as leis gerais: selecionei os monstros dentro das tragédias etc. Essa análise pressupõe fazer

2 Considerando que a maior parte dos escritos de Vigotski foi publicada postumamente, e como meu objetivo é situar historicamente o leitor sobre a produção do autor, optei por inserir, nas referências presentes no corpo do texto, o ano original em que ele foi produzido, seguido pelo ano da edição que utilizei. Adotei esse mesmo critério nas citações referentes às obras de Marx e Engels. As demais citações desse artigo cumprem as normalizações indicadas pela American Psychological Association (APA). abstração dos traços concretos da fábula como um gênero determinado para concentrar o esforço na essência da reação estética (Vygotski, 1927/1997, p. 374-375, grifos do autor, tradução nossa).

$\mathrm{Na}$ citação acima é possível observar que Vigotski, ao elaborar sua tese de doutorado, já estava interessado em buscar as essências contidas nas aparências dos fenômenos, um procedimento próprio à análise dialética de fundamentação marxista. Vigotski, ele mesmo, relembra a famosa tese de Marx e Engels: "Se a essência e a forma de manifestação coincidissem (...) toda ciência seria desnecessária" (Marx \& Engels citado por Vigotski, 1927/1999b, p. 383). Não há dúvidas de que as concepções filosófico-metodológicas marxistas exerceram significativa influência na produção do psicólogo bielorrusso, norteando seus escritos, apresentações públicas e outras atividades; mas é preciso examinar a específica maneira pela qual Vigotski incorporou ao campo da psicologia o legado filosófico e metodológico de Marx e Engels, e tentar compreender, de forma mais detalhada, as contribuições do autor bielorrusso para a construção de uma possível psicologia marxista.

Como veremos ao longo deste artigo, as vias abertas por Vigotski em sua busca por uma psicologia marxista foram bastante originais e forjadas no embate epistemológico com a produção científica de sua época. Em sua inquieta reflexão, o autor bielorrusso não poupou nem mesmo alguns colegas que, assim como ele, desejavam constituir uma psicologia marxista, mas que, para isso, desconsideravam a complexidade de tal intento e recorriam a dogmatismos e sociologismos (Vigotski, 1927/1999b, p. 203-417).

Totalmente imerso nas contradições, esperanças e grandes demandas que a Revolução Russa de 1917 suscitava, Vigotski procurou lutar, com toda a sua força e genialidade, para a concretização das transformações sociais tão almejadas pela população (Zanella, 2001, p.39). A nova condição política exigia das ciências (e das artes em geral) soluções concretas para os agudos problemas sociais, e a ciência psicológica precisava responder, com urgência, às demandas que lhe cabiam (Shuare, 1990, p.24-25). Ainda que, a partir de 1928, o terror stalinista tenha destruído muitas conquistas da Revolução Bolchevique, cabe lembrar o engajamento políticosocial que motivou a produção vanguardista de figuras como Vigotski, Eisenstein, Maiakovski, e também de milhões de outros personagens que talvez não sejam tão ilustres, mas trabalharam de forma igualmente 
árdua para democratizar a arte e a ciência e colocá-las totalmente a serviço das necessidades coletivas.

Segundo Shuare (1990), a assim chamada psicologia soviética (desde o período pósrevolucionário até o ano em que a autora escreveu a introdução à sua pesquisa, em dezembro de 1988) "mostra um traço que a diferencia marcadamente de outros sistemas científicos e que representa seu ponto de partida metodológico. Trata-se das relações entre a ciência psicológica e a filosofia" (p.11, tradução nossa). De acordo com a autora, "uma das características mais notáveis da psicologia soviética" reside no fato de essa psicologia ter se definido como "uma ciência que busca uma concepção filosófica determinada - o materialismo dialético e histórico". Foi a partir dessa referência central que a ciência psicológica soviética passou, então, a "desenvolver sua pesquisa científica" (p.11, tradução nossa). Não obstante, Shuare comenta que a existência de um ponto de partida comum para os pesquisadores não significaria, em tese, que as investigações deveriam ser orientadas por um "sistema rígido de normas e 'receitas' ou de procedimentos técnicos”, pois essa rigidez poderia conduzir à "dogmatização do conhecimento científico" (Yudin citado por Shuare, 1990, p. 13, tradução nossa).

É fato que a dimensão político-social esteve orgânica e diretamente associada aos avanços das artes e das ciências, ao menos na primeira década da Revolução Russa, mas não se pode restringir ao contexto local a produção de um autor cosmopolita e de vastos interesses como Vigotski, nem tomar o marxismo como o único referencial no desenvolvimento de suas formulações, apesar da inegável influência, na obra do psicólogo bielorrusso, das ideias de Marx e Engels. O leitor dos escritos vigotskianos sempre se surpreende com a profundidade e a quantidade de batalhas teóricometodológicas que o psicólogo travou com diferentes abordagens filosóficas (estruturalismo, idealismo, fenomenologia, entre outras) e teorias psicológicas (behaviorismo, psicanálise, reflexologia, reatologia e tantas mais); surpreende-se, novamente, ao vê-lo adentrar a psicologia da arte e haver-se com a fábula, o conto e a tragédia; e continua se surpreendendo ao se deparar com suas inovadoras análises do Hamlet de Sheakespeare e do simbolismo e do formalismo russos. O estudioso dos escritos vigotskianos impressiona-se, ainda, com a lista de pensadores, filósofos e cientistas que, de forma mais ou menos direta e em diferentes momentos de sua vida, influenciaram o trajeto intelectual do psicólogo bielorrusso: Espinosa, Hegel, Darwin, Janet, Piaget, Lévy-Bruhl...

Não obstante, a diversificada formação cultural de Vigotski não dilui ou minimiza, em absoluto, a importância do marxismo em sua obra. De diversas formas, o materialismo dialético revela-se e exerce-se no trabalho de Vigotski, como, por exemplo, quando o psicólogo contemplava, ao pesquisar um determinado objeto de estudo, toda a produção científica que estivesse ao seu alcance, buscando, assim, não apenas somar informações, mas alcançar uma superação dialética, um salto qualitativo ou um nível mais aprofundado de conhecimento.

\section{EM BUSCA DE O CAPITAL DA PSICOLOGIA}

Conquanto a obra do psicólogo bielorrusso venha sendo alvo das mais distintas interpretações, os comentadores vigotskianos reconhecem, geralmente, que as ideias de Marx e Engels desempenharam um importante papel na vasta produção do autor (Wertsch, 1985; Shuare, 1990); alguns estudiosos questionam, contudo, se essa influência foi determinante e primordial ou se deve ser vista tão somente como uma influência que se igualaria a outras tantas que permearam o trabalho do psicólogo (Van der Veer \& Valsiner, 2006).

Embora não haja unanimidade entre os comentadores em relação ao peso que se deva atribuir, na extensa produção do autor, à teoria marxista, parece bastante válida a interpretação de Duarte (2001, p. 80) de que "a obra de Vigotski não pode ser bem compreendida se tentarmos separá-la de seus fundamentos filosóficos, especialmente aqueles mais diretamente ligados ao universo da filosofia marxista". Essa perspectiva filosófica, que norteou o trabalho de Vigotski e para a qual o psicólogo dirigiu constantemente a atenção da comunidade científica, tem como um de seus elementos centrais a "noção de homem histórico, que se constitui enquanto sujeito a partir das relações que estabelece com outros homens" (Zanella, 2001, p. 87).

Em sua procura pela psicologia do homem histórico, Vigotski desenvolveu uma ampla e dinâmica obra; mas essa vasta produção foi pautada, de acordo com Veresov (1999), por três vetores centrais: consciência, objetividade e monismo, mais precisamente, pela busca, de caráter monista, por uma teoria científico-objetiva da consciência humana. De acordo com Veresov, é possível identificar, durante certo período da obra de Vigotski, conflitos entre o pressuposto científico-monista do autor bielorrusso e as teorias psicológicas de caráter dualista das quais ele 
se aproximou, visto que essas teorias mantinham cindida a relação entre consciência e realidade social. Vigotski, segundo Veresov, aproximou-se inicialmente de duas orientações marcadamente dualistas: a reflexologia (até 1924) e o "estruturalismo comportamental” (de 1925 a 1927); esboçando, gradativamente, uma abordagem monista, com sua teoria histórico-cultural (de 1927 a 1934). O comentador ressalta que, embora Vigotski tenha se identificado com alguns pressupostos das correntes acima mencionadas, o autor bielorrusso, com suas indagações teórico-metodológicas, sempre esteve à frente dessas correntes. Veresov afirma, ainda, que o desenvolvimento da produção vigotskiana está intrinsecamente vinculado aos próprios conflitos com os quais o psicólogo se deparou ao longo de sua trajetória (Veresov, 1999, p. 193-207).

Não se pretende esmiuçar, neste artigo, os conflitos acima mencionados (por mais importante que seja essa tarefa), mas sim, apontar as motivações políticas, filosóficas e metodológicas que levaram o psicólogo a priorizar o conjunto consciênciaobjetividade-monismo. Entre as diversas razões que contribuíram para que Vigotski se norteasse por essa tríade, cabe destacar, aqui, o envolvimento visceral do autor com a proposta da Revolução de 1917 e o desafio - aceito por ele e por diversos outros pesquisadores soviéticos - de elaborar uma psicologia dialético-marxista que contemplasse a dimensão histórico-materialista do psiquismo. Essa perspectiva "historicista" do desenvolvimento psíquico pode ser considerada, na opinião de Shuare (1990, p. 59), o principal eixo articulador da produção vigotskiana. De acordo com a comentadora, o eixo em questão pressupõe que os fenômenos psíquicos são "sociais por sua origem" e que estudá-los implica no entendimento de que "a história do psiquismo humano é a história social de sua constituição" (p. 61, grifo da autora, tradução nossa).

Foi na dialética marxista que Vigostski procurou recursos para investigar o estado de crise em que se encontrava a psicologia, ciência que, segundo o autor, geralmente desconsiderava a natureza social e histórica dos fenômenos psíquicos. No manuscrito "O significado histórico da crise em psicologia" (Vigotski, 1927/1999b), já mencionado neste texto, Vigotski identificou a necessidade de a ciência psicológica dispor de seu próprio $O$ Capital, ou seja, de um conjunto articulado de pressupostos teóricometodológicos forjados a partir dos princípios dialético-materialistas. $\mathrm{O}$ autor acreditava que a psicologia precisaria construir uma "ciência geral" (também por ele denominada "teoria intermediária") que, analisando dialeticamente as produções das diversas "ciências particulares" (as várias "disciplinas" ou "domínios" no campo da psicologia), procedesse, então, a uma "elaboração e generalização" daquelas diversificadas produções, algo que seria "impossível dentro de cada disciplina [psicológica] em separado" (p. 244).

Fiel ao enfoque dialético-materialista, Vigotski afirmava que a psicologia, ao elaborar sua ciência geral, necessitava adotar "a perspectiva realistaobjetiva - isto é, materialista em gnosiologia e dialética em lógica - na análise do conhecimento científico". Para tanto, o autor bielorrusso nos relembra que, para o materialismo dialético, é a realidade que "determina nossa experiência (...), o objeto da ciência e o seu método"; ele destaca, ainda, a impossibilidade de estudarmos "os conceitos de qualquer ciência prescindindo das realidades representadas por esses conceitos" (Vigotski, 1927/1999b, p. 246). Assim procedendo, Vigotski evidencia sua opção por uma abordagem psicológica comprometida em entender o homem concreto (o ser humano inserido em sua realidade histórica objetiva), reiterando que o psiquismo é - ele também - uma realidade objetiva que pode ser desvelada por meio da compreensão dialética.

Entendendo a dialética como perspectiva "universal ao máximo" que "abarca a natureza, o pensamento, a história" Vigotski definiu a "ciência geral" psicológica como "materialismo psicológico" ou "dialética da psicologia" (Vigotski, 1927/1999b, p. 393). Essa "ciência geral" teria potencial para ultrapassar as arraigadas, estáticas e a-históricas orientações psicológicas, de caráter metafísico e/ou mecanomaterialista, que limitavam profundamente, no entendimento do autor, o desenvolvimento da psicologia (p. 342-343). Com sua perspectiva dinâmica e histórica, a "dialética da psicologia" estudaria as "formas mais gerais do devir" e como elas se manifestam "no comportamento e nos processos de conhecimento" (p.247).

Antes de continuarmos analisando a proposta vigotskiana de uma "ciência geral" como expressão do "materialismo psicológico" ou "dialética da psicologia", cabe assinalar alguns aspectos do método dialético-marxista.

No posfácio à segunda edição de $O$ Capital, Marx afirma que, na perspectiva dialético-materialista, o ideal e o material são duas manifestações diferentes de uma única e mesma natureza: "o ideal não é nada mais que o material, transposto e traduzido na cabeça do homem" (Marx, 1873/1982b, p. 20, grifo nosso). Referindo-se ao seu método de pesquisa, em Para 
uma crítica da economia política, o filósofo alemão afirma que a realidade concreta "aparece no pensamento como o processo da síntese, como resultado, não como ponto de partida, ainda que seja o ponto de partida efetivo (...)" (Marx, 1859/1982a, p.14). Esse processo de síntese, alcançado por meio de uma análise objetiva da realidade, tem potencial transformador, pois o sujeito, após apreender a "unidade do diverso", modifica-se a si mesmo e, ao mesmo tempo, pode gerar novos movimentos na realidade social.

Prado Jr. (1973) ressalta que o conhecimento se apresenta na consciência humana não como uma cópia ipsis litteris da realidade, mas, como demonstram as palavras de Marx acima citadas, como uma tradução, ou seja, uma apreensão ou representação mental do concreto. Essa distinção é central para diferenciarmos os referenciais idealista (ou metafísico) e mecanomaterialista, do referencial dialético-marxista, e para compreendermos, também, a presença do monismo materialista em Vigotski.

Nas análises de Vigotski (1927/1999b, p. 391) sobre o método dialético, o autor ressalta que, embora esse método represente "a alavanca por meio da qual a filosofia dirige a ciência”, não faz sentido proceder a uma aplicação direta do materialismo dialético à psicologia, assim como é impossível aplicá-lo diretamente à história ou à sociologia. Faz-se necessária, muito mais, a criação de uma metodologia, ou seja, uma ciência geral ou "teoria intermediária", evitando-se, assim, o risco de produzir "uma tosca deformação do marxismo e da psicologia" (p.392).

O psicólogo bielorrusso afirma que Marx formulou uma ciência da história - o materialismo histórico - ciência que certamente é subsidiada pelo materialismo dialético, mas que fora criada para estudar categorias e leis próprias da sociologia ${ }^{3}$.

3 A questão do método não foi desenvolvida de forma sistemática por Marx; ele limitou-se a aplicar o método à história, como afirma Prado Jr. (1973). Esse fato pode ter favorecido distintas interpretações e denominações da produção teórico-metodológica marxiana, tais como: 1) "materialismo histórico e dialético", enquanto teoria da história ("materialismo histórico") que agrega de forma inseparável uma teoria do conhecimento ("materialismo dialético") (Althusser, 1979; Prado Jr, 1973); 2) “dialética”, que incorpora, em si, uma concepção materialista e histórica (Vieira Pinto, 1979); 3) "materialismo histórico", omite-se a "dialética" considerando que o historicismo é, por si mesmo, dialético (Gramsci, 1999). Vigotski, contudo, realizou uma análise que contemplava, ao mesmo tempo, a imbricação e a diferenciação entre a teoria da história (conteúdos sociológicos) e a teoria do conhecimento (método dialético) na produção de Marx, incluindo, em suas análises, os estudos realizados por
Vigotski enfatiza, ainda, que a dialética opera com categorias abstratas que são válidas para qualquer campo do saber, mas que se comete um tremendo erro epistemológico ao se tentar aplicar a dialética, diretamente, a uma determinada área do conhecimento sem estabelecer princípios metodológicos intermediários que respondam, simultaneamente, às diretrizes dialéticas gerais e às especificidades da área em questão. O mesmo erro ocorreria ao se aplicarem, ingenuamente, os conceitos oriundos do materialismo histórico (tais como as noções de classe social, mercadoria, mais-valia). Essa atitude apressada e simplista em nada contribuiria, de acordo com Vigotski, para que a psicologia construísse o seu $O$ Capital. O psicólogo bielorrusso não esperava encontrar no marxismo a solução para o problema da compreensão do psiquismo, mas sim, apreender "na globalidade do método de Marx como se constrói a ciência, como enfocar a análise da psique" (Vigotski, $1927 / 1999$ b, p. 395, grifo do autor) - em outras palavras, como elaborar uma metodologia própria para a psicologia.

Considerando que a "teoria da história" (o materialismo histórico) já havia sido criada, Vigotski defendeu a tese de que seria necessário formular outros "materialismos" científicos, tais como o "materialismo biológico" e o "materialismo psicológico". Essas "teorias intermediárias" precisariam ser constituídas a partir de um amplo diálogo entre as distintas orientações internas que pertencem a um dado campo do saber. A expectativa do autor em relação à ciência psicológica era que esse diálogo metodológico entre suas distintas correntes superasse dialeticamente as difíceis e antigas contradições que reinavam nessa ciência. Vigotski via com otimismo a crise na psicologia, e acreditava que uma profunda crítica dialética das proposições idealistas e mecanicistas poderia promover a constituição de uma nova ciência psicológica. Vigotski reconheceu na sofisticação metodológica uma oportunidade ímpar para uma compreensão verdadeiramente histórica e social do psiquismo humano. Fazia-se necessário, assim, identificar urgentemente os elementos não científicos e metafísicos que, ao longo dos séculos, haviam aderido à psicologia como "ao casco de um transatlântico" (Vigotski, 1927/1999b, p. 416). Vigotski tinha consciência de que essa psicologia ainda não existia e que sua construção exigiria grandes esforços e um

Engels em A Dialética da Natureza (Engels, 1876/1991); portanto, é com essa interpretação, que o artigo aqui apresentado se propõe a trabalhar. 
olhar crítico e maduro, por parte da comunidade científica, para a psicologia em crise, pois a criação da ciência geral psicológica reconfiguraria o quadro global da psicologia existente. Sabia, também, que esse questionamento metodológico precisaria abarcar não apenas o campo da psicologia, mas igualmente outras áreas do conhecimento. Ele não estava alheio ao fato de que tal psicologia apenas poderia começar a se constituir no limiar de uma "nova sociedade" (p. 417).

Delari Jr. (2000, p.61) chama a atenção para o fato de que Vigotski, ao se confrontar com a crise na ciência psicológica e constatar que as diferentes "psicologias de seu tempo" não conseguiam "estudar o que há de especificamente humano no homem", lançou "as bases para a construção de uma psicologia humana" que tinha "por objeto a consciência". Assim, a proposta era que a ciência psicológica, adotando a consciência como objeto de estudo e valendo-se de uma metodologia própria de pesquisa (de orientação materialista-dialética), superasse uma série de antigas e arraigadas concepções dualistas - corpo-mente, subjetivo-objetivo, razão-emoção, entre tantas outras -, constituindo-se como uma ciência monista ${ }^{4}$, materialista e objetiva do homem histórico. Não obstante, sérias restrições políticas começaram a despontar: o dogmatismo stalinista passou, gradualmente, a se impor na produção científica, cerceando os avanços e concepções de vanguarda (nas artes e nas ciências) que haviam marcado a fase inicial da Revolução Russa. No início da década de 1930, o próprio Vigotski passou a "sofrer ataques por sua suposta ligação com filósofos e psicólogos idealistas menchevistas" (Van der Veer \& Valsiner, 2006, p. 334).

Não há dúvida de que a busca pelo $O$ Capital da psicologia, por parte do psicólogo bielorrusso e de seus colaboradores, foi uma tarefa extremamente audaciosa, pois indicou a forma como o marxismo influenciou a abordagem histórico-cultural. No que se refere à inédita alternativa que Vigotski ofertou para se lidar com a crise da psicologia de sua época (a possibilidade da formulação de uma ciência geral psicológica), cabe realçar que esse projeto, que apenas poderia ser empreendido coletivamente, não alcançou as proporções sonhadas pelo autor. Ao mesmo tempo, a abordagem histórico-cultural tornou-se mais uma entre as "escolas" da psicologia (ciência que, ao que

\footnotetext{
É importante ressaltar que o monismo tem uma ampla tradição na história da filosofia e não se restringe ao monismo marxista. Vale também mencionar que a concepção monista de Espinosa exerceu, como aponta Delari Jr. (2000), forte influência na obra de Vigotski.
}

tudo indica, ainda vive em profunda crise epistemológica) (Yurevich citado por Veresov, 2010, p. 267-268)

\section{ALGUNS FUNDAMENTOS METODOLÓGICOS DA ABORDAGEM HISTÓRICO-CULTURAL}

Da mesma forma que Marx, em $O$ Capital, analisou algumas categorias genéricas da economia capitalista (como, por exemplo, a mercadoria), procurando estudá-las dialeticamente para assim desvendar o funcionamento social, Vigotski também procurou estudar dialeticamente categorias ou estruturas específicas do ser humano que pudessem desvendar o funcionamento psíquico. Ele as reconheceu nas "funções psíquicas superiores" memória lógica, atenção voluntária, formação de conceitos, imaginação, entre outras -, buscando compreender, na inter-relação dinâmica e no desenvolvimento dessas funções, o processo de formação social da consciência.

Não obstante, observa-se nas investigações vigotskianas que, ao mesmo tempo em que estudava o desenvolvimento das funções psíquicas superiores, o autor procurava extrair de suas pesquisas possíveis princípios gerais para a ciência psicológica. Em um conjunto de notas de 1929 (posteriormente publicado com o título "Psicologia concreta do homem"), o autor fez o seguinte apontamento (que antecipa sua "lei genética geral do desenvolvimento cultural"): "Lei geral: qualquer função no desenvolvimento cultural da criança aparece em cena duas vezes, em dois planos primeiro no social, depois no psicológico, primeiro entre as pessoas como categoria interpsicológica, depois - dentro da criança [como categoria intrapsicológica]". Procedendo a uma "paráfrase de Marx" (sexta tese sobre Feuerbach) (Marx, $1845 / 1978 b$ ), ele anotou também que "a natureza psicológica da pessoa é o conjunto das relações sociais, transferidas para dentro e que se tornaram funções da personalidade e formas da sua estrutura" (Vigotski, 1929/2000, p. 26-27).

A intrínseca relação entre os planos psicológico e social, acima mencionada, é também indicativa do monismo materialista de Vigotski; contudo, essa relação somente pôde se consolidar com a ideia de mediação sígnica, a qual, entre 1927 e 1928, tornouse, para o autor, o definitivo fator dialético unificador das categorias inter e intrapsicológicas. De acordo com Veresov (1999), a mediação sígnica passou a ser vista pelo psicólogo bielorrusso como um tipo de relação ou um "princípio explicativo" do vínculo existente entre a consciência e o meio social, podendo 
ser denominada "método objetivo monístico de análise da mente" (p. 194, tradução nossa). Esse método ganharia corpo entre 1933 e 1934, com a ideia de unidade de análise desenvolvida pelo autor (abordada logo abaixo).

O signo como instrumento mediador foi equacionado metodologicamente a partir de 1930; a esse equacionamento Vigotski denominou "método instrumental". Esse método foi representado pelo psicólogo por meio da fórmula $\mathrm{A}-\mathrm{X}-\mathrm{B}$, na qual a relação estímulo-resposta ou excitante-reflexo (A B), até então vista pela perspectiva reflexológica como uma relação imediata, passa a ser mediada, de acordo com Vigotski, por um signo (X) (por exemplo, a linguagem verbal, as diferentes formas de numeração e cálculo, as obras de arte, a escrita, etc.). Para o autor, cabe falar, a partir de então, de duas outras conexões: A - X e X - B (Vigotski, 1930/1999a). O método instrumental buscou explicitar, de forma esquemática, a importância do signo como mediador na formação da consciência, portanto, como o principal agente responsável pela capacidade exclusivamente humana de autodomínio consciente da conduta, capacidade que foi desenvolvida por meio da apropriação das funções psíquicas superiores.

$\mathrm{Na}$ produção de Vigotski torna-se cada vez mais evidente a preocupação metodológica com a análise qualitativa do desenvolvimento psicológico; e, como indica Wertsch (1985, p. 17), com uma abordagem metodológica que prioriza a ideia de processo, ao invés da de produto. Para dar conta de tal intento, Vigotski criou o método genético (ou "genéticocausal" ou "genético-experimental"). Esse método exige do investigador, em suas pesquisas experimentais, a criação de mediações simbólicas que busquem a gênese, ou seja, a origem do desenvolvimento, e impõe-lhe a necessidade de uma explicação dos fenômenos (e não somente a sua descrição); enfim visa conhecer as essências (e não somente as aparências) dos fenômenos psicológicos. Esse método amparou as pesquisas de Vigotski e de seus colaboradores acerca do vínculo existente entre aprendizagem e desenvolvimento, sustentando os seus estudos sobre o importante papel dos conceitos no processo de formação da consciência.

$\mathrm{Na}$ fase final de sua produção, Vigotski expõe o seu "método de análise por unidade", o qual permitiria investigar o denominador comum existente entre funções sistêmicas diretamente inter-relacionadas. No caso do pensamento e da linguagem, o autor identificou o significado da palavra como a unidade básica, o fator comum a essas duas instâncias (Vigotski, 1934/2001). No significado da palavra o autor reconheceu, ainda, o princípio explicativo organizador da consciência humana. A mediação semiótica da palavra no pensamento, aliada à ideia de desenvolvimento da consciência, sofisticou-se ao final de sua produção, principalmente quando Vigotski passou a conceber a relação entre as funções psíquicas elementares (de natureza biológica) e as superiores (de origem cultural) de forma dinâmica e sistêmica. A ideia de sistema psicológico desenvolvida pelo autor foi, assim, fundamental para o avanço de seu monismo materialista (Vigotski, 1934/2001). Segundo Shuare (1990), o psicólogo bielorrusso, ao contemplar as operações semióticas no desenvolvimento das funções psíquicas superiores, avançou na compreensão da complexidade dos processos psíquicos e no entendimento do trânsito da "história natural da psique para o âmbito das formações históricas do comportamento" (p.67, tradução nossa).

Vale assinalar, ainda, a importância que assume a ideia dialético-marxista de "crise" na obra vigotskiana. A crise e sua potência transformadora foram reconhecidas por Vigotski, como mencionado anteriormente, nos impasses epistemológicos experienciados pela ciência psicológica, mas a crise como condição propulsora de saltos qualitativos também foi identificada pelo autor ao longo da filogênese e da ontogênese do desenvolvimento psíquico humano. Essa concepção dialética de crise propiciou uma compreensão dinâmica do processo de constituição da consciência.

O modesto conjunto de fatores acima exposto representa apenas parte das formulações teóricometodológicas desenvolvidas por Vigotski; no entanto, mesmo considerando-se a estreiteza do conjunto aqui apresentado, é possível identificar o intento do autor bielorrusso de construir uma abordagem científica e objetiva da consciência humana, abordagem que se fundamenta numa perspectiva monista e no pressuposto de um psiquismo que tem como fonte para o seu desenvolvimento os processos históricos e culturais. $\mathrm{O}$ autor demonstrou, assim, que conseguira apreender "na globalidade do método de Marx como se constrói a ciência, como enfocar a análise da psique" (Vigotski, 1927/1999b, p. 395, grifo do autor).

\section{CONSIDERAÇÕES FINAIS}

Após esse breve resgate da questão metodológica na obra de Vigotski, serão sintetizados, a seguir, os principais conteúdos aqui abordados. Neste tópico serão também extraídas algumas conclusões preliminares, entre as diversas possibilidades 
interpretativas e indagatórias que o presente estudo possa suscitar.

Destacando-se o papel do historicismo na obra vigotskiana e tomando-se como referência a tríade temática "consciência, monismo e objetividade", procurou-se realizar, aqui, algumas reflexões globais sobre o método materialista dialético na produção vigotskiana. Comentou-se a forma sofisticada pela qual Vigotski apreendeu o legado marxista (o autor evitou tanto as importações de conceitos do materialismo histórico quanto as aplicações diretas do materialismo dialético ao campo da produção psicológica). Abordou-se a proposta vigotskiana de criação de uma ciência geral para a psicologia, como também para outras áreas do conhecimento. Resgatouse a "lei genética do desenvolvimento cultural" (e, consequentemente, as tentativas vigotskianas de encontrar princípios gerais para a psicologia). Abordou-se, ainda que de forma muito breve, o "método instrumental" e a importância da mediação semiótica no desenvolvimento da consciência (o signo como instrumento da constituição histórica do psiquismo, ao longo da filogênese e da ontogênese, e o significado da palavra como princípio organizador da consciência humana). Foram destacados os avanços propiciados pelo método genético (método que prioriza a ideia de processo, ao invés de produto) e as ricas possibilidades abertas pelo "método de análise por unidade" (diretriz metodológica que permite identificar fatores comuns entre fenômenos diretamente relacionados). Mencionou-se a preocupação vigotskiana em entender, de forma dinâmica e sistêmica, a gênese e a evolução das funções psíquicas superiores, bem como a importância da noção de sistema psicológico que ele desenvolveu.

Esses tópicos não esgotam, em absoluto, a ampla contribuição metodológica de Vigotski para a produção psicológica (e, também, para a teoria do conhecimento). Tais contribuições ainda merecem, certamente, estudos mais aprofundados que identifiquem as singularidades da metodologia vigotskiana, inclusive porque a forma pela qual o autor traduziu a dialética marxista para a psicologia pode contribuir para solucionar vários problemas fundamentais em diferentes áreas do conhecimento. A vanguardística abordagem metodológica de Vigotski, de acordo com Veresov (1999), não deve, portanto, ser vista como um mero tema de época ou um detalhe em sua vasta obra, pois, ao que tudo indica, as análises epistemológicas e as formulações metodológicas do autor continuam extremamente atuais e expressam "uma moderna concepção com um potencial metodológico, que não foi completamente explorado" (p. 197, tradução nossa).

Explorar a obra de Vigotski em profundidade não é tarefa simples; como aponta Delari Jr. (2010), as edições dos escritos do autor apenas contemplam, até o momento, parte de sua vasta produção (no Brasil, tão somente dez por cento); além dessa dificuldade, o pesquisador que não conhece a língua russa tem que se haver, frequentemente, com problemas de tradução. Ainda recentemente, algumas anotações de Vigotski pertencentes ao acervo de sua família foram organizadas e comentadas por uma pesquisadora de sua obra, do que resultou na revelação de importantes aspectos e os "bastidores" de sua produção. Em um desses escritos, quando o autor bielorrusso aborda a questão da liberdade, ele menciona a necessidade de "trazer o spinozismo para a vida na psicologia marxista" (Vigotski, 1932 citado por Zavershneva, 2010, p. 66, tradução nossa). Temas desse gênero não são apenas curiosidades; eles indicam, na verdade, importantes questões metodológicas que podem ser aprofundadas. Os estudos que vêm abordando, na obra vigotskiana, a influência de Espinosa e o papel da emoção, dos afetos e da volição na consciência; as pesquisas que analisam a função do drama na formação da personalidade e as interfaces entre arte e psicologia (o presente dossiê apresenta importantes trabalhos com essas temáticas) - todos eles abrem, também, diversas portas para se compreender e ampliar a reflexão metodológica na perspectiva histórico-cultural.

Por fim, vale destacar o benefício, para o pesquisador que se inspira na obra vigotskiana, de se familiarizar com as sofisticadas e arejadas soluções teórico-metodológicas que o psicólogo elaborou, procurando entendê-las não como conceitos isolados, mas no conjunto da discussão epistemológica realizada pelo autor. Como demonstrou o próprio psicólogo bielorrusso, a produção científica de filiação dialético-marxista exerce-se em dois níveis mais ou menos simultâneos: o "particular" e o "geral". Como a investigação pontual não se limita necessariamente a si mesma, tendo potencial para desvelar também princípios mais gerais de um dado campo de conhecimento, o "particular" e o "geral" revelam-se em contínua inter-relação. Resgatar, no campo da investigação científica, a dialética que se estabelece entre esses dois níveis, certamente traz implicações de diversas ordens, em especial quando se consideram as inúmeras interpretações que a perspectiva históricocultural vem sofrendo ao longo do tempo; no entanto, uma avaliação mais consistente dessas e de outras implicações pode vir a exigir do pesquisador da obra 
vigotskiana um contato próximo com tanto as proposições epistemológicas formuladas por Vigotski quanto com as teorizações filosófico-metodológicas elaboradas por Marx e Engels.

\section{REFERÊNCIAS}

Althusser, L. (1979). Materialismo histórico e materialismo dialético. In Badiou, A.; Althusser, L. Materialismo Histórico $e$ Materialismo Dialético. (1a ed.). (E. A. P. Santos, Trad.). São Paulo: Global.

Delari Jr., A. (2000). Consciência e linguagem em Vigotski: aproximações ao debate sobre a subjetividade (Dissertação de Mestrado), Universidade Estadual de Campinas, SP.

Delari Jr., A. (2010) Traduções publicadas no Brasil [1984-2010]. In História da Pedagogia: Lev Vigotski.(pp.76-89). São Paulo: Ed. Segmento.

Duarte, N. (2001). Educação escolar, teoria do cotidiano e a escola de Vigotski. (3ae ed.). Campinas: Editora Autores Associados.

Engels, F. (1991). A dialética da natureza. (5a ed.). Rio de Janeiro: Paz e Terra. (Obra originalmente concluída em 1876).

Gramsci, A. (1999). Cadernos do Cárcere. (C. N. Coutinho, Trad.). Rio de Janeiro: Civilização Brasileira, v. 1.

Leontiev, A. N. (1999). Artigo de Introdução sobre o trabalho criativo de L. S. Vigotski. In Vigotski, L. S. Teoria e Método em Psicologia. (C. Berliner, Trad.). São Paulo: Martins Fontes, 1999.

Marx, K. (1978a). Manuscritos econômico-filosóficos e outros textos escolhidos (J. C. Bruni, Trad.). Coleção Os Pensadores. São Paulo: Abril Cultural. (Obra originalmente redigida em 1844)

Marx, K. (1978b) Teses sobre Feuerbach (J. C. Bruni, Trad.). In Manuscritos econômico-filosóficos e outros textos escolhidos. Coleção Os Pensadores. São Paulo: Abril Cultural. (Obra originalmente redigida em 1845).

Marx, K. (1982a). Para a crítica da economia política. (E. Malagodi, Trad.). São Paulo: Abril Cultural. (Obra originalmente escrita em 1859).

Marx, K. (1982b). Posfácio à segunda edição. O capital: crítica da economia política. (R. Sant'Anna, Trad.) (7a ed.). São Paulo: DIFEL. (Posfácio originalmente redigido em 1873).

Prado Jr., C. (1973). Teoria marxista do conhecimento e método dialético materialista. In Discurso - Revista do Departamento de Filosofia da Faculdade de Filosofia, Letras e Ciências Humanas da Universidade de São Paulo (4) 41-78. Recuperado em 10 de setembro, 2010, de http://www.vigotski.net/textmarx.html

Shuare, M. (1990). La Psicologia Soviética como yo la vejo. Moscú: Editorial Progreso.
Van der Veer R. \&Valsiner, J. (2006). Vygotsky: uma síntese (5a ed.). (C. C. Bartalotti, Trad.). São Paulo: Edições Loyola.

Veresov, N. (1999). Undiscovered Vygotsky: etudes on the pre-history of cultural-historical psychology. Frankfurt am Main: Peter Lang Publishers.

Veresov, N. (2010). Forgotten Methodology: Vygotsky's Case. In Methodological Thinking in Psychology: 60 Years Gone Astray? Toomela, A.; Valsiner, J. (Org.). Charlotte: Information Age Publishing, pp. 267-295.

Vieira Pinto, A. (1979). Ciência e existência: problemas filosóficos da pesquisa científica (3a ed.). São Paulo: Paz e Terra, 1979.

Vigotski, L. S. (1999a). O Método Instrumental em psicologia. In Teoria e Método em Psicologia. São Paulo: Martins Fontes. (Conferência proferida em 1930).

Vigotski, L. S. (1999b). O Significado Histórico da Crise da Psicologia:Uma Investigação Metodológica. In Teoria e Método em Psicologia (2a ed.). (C. Berliner, Trad.). São Paulo: Martins Fontes. (Manuscrito originalmente concluído em 1927).

Vigotski, L. S. (1999c). Psicologia da arte (P. Bezerra, Trad.). São Paulo: Martins Fontes. (Tese originalmente concluída em 1925).

Vigotski, L. S. (2000). Psicologia concreta do homem. In Educação e Sociedade - Revista Quadrimestral de Ciência da Educação (71), 21-44. (Manuscrito originalmente redigido em 1929).

Vigotski, L. S. (2001). A Construção do Pensamento $e$ da Linguagem. (P. Bezerra, Trad.). São Paulo: Martins Fontes. (Obra originalmente concluída em 1934).

Vygotski, L. S. (1997). El significado historico de la crisis de la psicología: una investigación metodológica. In Obras escogidas tomo I. (J. M. Bravo, Trad.). Madrid: Vysor Aprendizaje y Ministerio de Cultura y Ciência. (Manuscrito originalmente concluído em 1927).

Wertsch, J. V. (1985). Vygotsky and the social formation of mind. Harvard University Press.

Zanella, A. V. (2001). Vygotski: Contexto, contribuições à psicologia e o conceito de zona de desenvolvimento proximal. Itajaí: Univali.

Zavershneva, E. I. (2010). The Way to Freedom. Journal of Russian and East European Psychology, 48 (1), 61-90.

Recebido em 25/10/2010 Aceito em 25/01/2011
Endereço para correspondência:
Nancy Romanelli. Rua das Laranjeiras, 113, ap. 23, Bairro: Parque Terra Nova I, CEP 09820480, São Bernardo do Campo-SP, Brasil.E-mail: nanromanelli@terra.com.br. 